\title{
The Integration of TLS and Continuous GPS to Study Landslide Deformation: A Case Study in Puerto Rico
}

\author{
Research Article
}

\author{
G. Wang ${ }^{1}$, D. Philips ${ }^{2}$, J. Joyce ${ }^{3}$ and F. O. Rivera ${ }^{3}$
}

1 Puerto Rico Seismic Network, Department of Geology, University of Puerto Rico, Mayaguez, PR 00681, U.S.

2 UNAVCO, Boulder, CO 80301 , U.S.

3 Department of Geology, University of Puerto Rico, Mayaguez, PR 00681, U.S.

\begin{abstract}
:
Terrestrial Laser Scanning (TLS) and Global Positioning System (GPS) technologies provide comprehensive information on ground surface deformation in both spatial and temporal domains. These two data sets are critical inputs for geometric and kinematic modeling of landslides. This paper demonstrates an integrated approach in the application of TLS and continuous GPS (CGPS) data sets to the study of an active landslide on a steep mountain slope in the El Yunque National Forest in Puerto Rico. Major displacements of this landslide in 2004 and 2005 caused the closing of one of three remaining access roads to the national forest. A retaining wall was constructed in 2009 to restrain the landslide and allow the road reopen. However, renewed displacements of the landslide in the first half of 2010 resulted in deformation and the eventual rupture of the retaining wall. Continuous GPS monitoring and two TLS campaigns were performed on the lower portion of the landslide over a three-month period from May to August 2010. The TLS data sets identified the limits and total volume of the moving mass, while the GPS data quantified the magnitude and direction of the displacements. A continuous heavy rainfall in late July 2010 triggered a rapid 2-3 meter displacement of the landslide that finally ruptured the retaining wall. The displacement time series of the rapid displacement is modeled using a fling-step pulse from which precise velocity and acceleration time series of the displacement are derived. The data acquired in this study have demonstrated the effectiveness and power of the integrating TLS and continuous GPS techniques for landslide studies.
\end{abstract}

\section{Keywords:}

TLS • Continuous GPS • Landslide • Generic Mapping Tool (GMT) • Puerto Rico $・$ Rainfall • Digital Surface Model

(c) Versita Warsaw and Springer-Verlag Berlin Heidelberg.

Received 1 October 2010; accepted 26 November 2010

\section{Introduction}

In recent years the use of Terrestrial Laser Scanning (TLS) and Global Positioning System (GPS) for applications in ground deformation study has increased notably. TLS provides a dense set of data ("point clouds") with each measurement providing a 3D position in space and the intensity of the reflected signal. The dense data set can be modeled to generate a best-fitting surface over the whole study area. Ground deformation can be identified when two or more ground surface models derived from TLS point clouds are available. TLS acquires ground deformation information in a spatial domain with centimeter accuracy (Lichti and Jamtsho, 2006), but low temporal resolution. The temporal shortcoming can be resolved by implementing continuous GPS (CGPS) that can provide sub-centimeter precision for discrete sites in a continuous temporal domain.

TLS is a relatively new surveying technique, which has been frequently utilized to study landslide deformation in recent years (e.g., Abellan et al., 2006; Teza et al., 2007; Teza et al., 2008; Monserrat and Crosetto, 2008; Casula et al., 2010). GPS technique has been widely applied to monitor landslide movements in the last decade, both as a complement and an alternative to conventional 
surveying methods (e.g., Gili et al., 2000; Malet et al., 2002; Coe et al., 2003; Sato et al., 2003; Mora et al., 2003; Squarzoni et al, 2005; Bruckl et al., 2006; Tagliavini et al., 2007; Psimoulis et al., 2007; Peyret et al., 2008; Wang 2010). This article presents the results of an integrated TLS and continuous GPS approach to monitor, characterize and model an active landslide. The landslide is located on a steep mountain slope in the rainforest within the El Yunque National Forest in Puerto Rico. Major displacements of the landslide in 2004 and 2005 across the roadway of one of three remaining access roads to the National Forest resulted in its closure. In order to reopen the roadway a retaining wall was designed and constructed to restrain the landslide. However, prior to the termination of its construction a significant portion of the west end of the wall failed. The failure was originally attributed to insufficient depth of the support piles but further analysis suggests that the design underestimated the full extent of the landslide mass. The failed section of the wall was repaired and strengthened but prior to final termination in August 2009 significant soil displacements behind the failed section thwarted final grading efforts. The retaining wall was finally finished in the end of 2009 but the previously failed section continued to show flexural deformation over the spring of 2010 until it finally ruptured and burst open in July 2010 during a heavy rainfall event.

Field inspection of the site indicated that the slopes directly above the wall were failing on a rotational slide that produced small escarpments in the upper slope and soil bulges along the top of the retaining wall behind the previously failed section. The full extent of the landslide was delineated during the inspection. The landslide is well defined by northwest trending flank scarps marked by inclined slip striations along the scarp face. The head scarp was encountered over 250 meters up slope and is composed of partially to highly weathered bedrock. Failure of the retaining wall was attributed to underestimation of the size of the landslide mass but it remained uncertain if there were displacements in the upper portions of the main landslide. The renewed landslide activity and failure of the retaining wall and the loss of an alternate access road is of major concern to the El Yunque National Forest administration. Mitigation alternatives for the landslide require a more precise estimation of its extent, volume and kinematics. In order to precisely identify the margins and study the kinematics of the active displacements of the lower portions, continuous GPS monitoring and two TLS surveys were performed at the landslide site during a three-month period from May 24 to August 24, 2010. These two methods provide for a non-invasive analysis of an ecologically sensitive site with limited accessibility for heavier equipment. A view of the landslide site and two images of the laser point clouds acquired during the two TLS surveys are illustrated in Figure 1. Black pixels are no TLS data areas. Continuous rainfall data from a nearby United States Geological Survey (USGS) weather station were also integrated to this study.

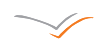

VERSITA

\section{TLS Data Acquisition and Processing}

A RIEGL VZ-400 laser scanner, provided by UNAVCO (http://www. unavco.org), was used to collect TLS data in the field. This scanner provides high resolution, high-speed 3D data acquisition using a narrow infrared laser beam and a fast scanning mechanism (http: //www.riegl.com). The range of the scanner is up to $600 \mathrm{~m}$ with the repeatability of $3 \mathrm{~mm}$ for target points. The high density and accurate 3D digital data sets involve precise volume measurements when comparing two or more surveys. This scanner has the capability of recording both first and last laser returns, as well as a few intermediate returns.

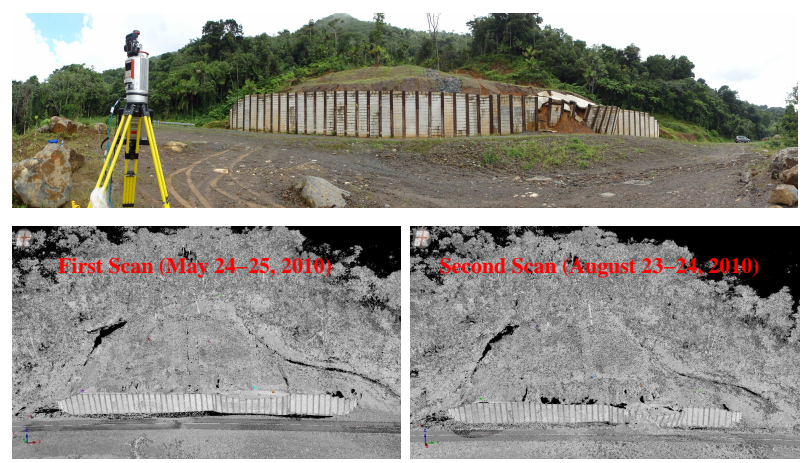

Figure 1. The upper photo shows a panorama view at the landslide site took on August 24, 2010. The retaining wall extends along east-west direction. The bottom images represent the coverage of TLS point clouds acquired during the first (May 24-25, 2010) and second (August 23-24, 2010) TLS surveys.

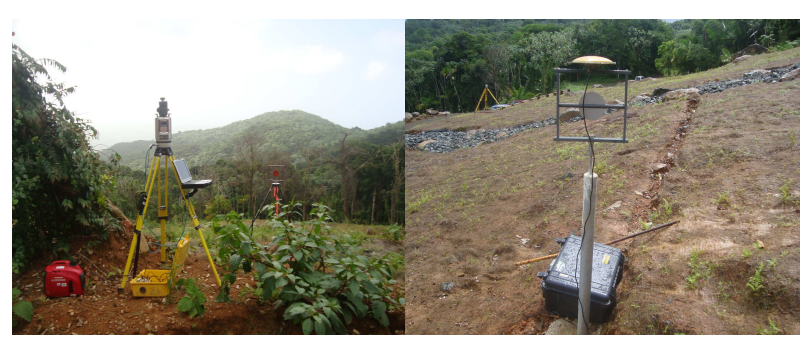

Figure 2. Photos showing reflective targets placed in the field for TLS surveys. The left hand photo shows the RIEGL VZ-400 laser scanner and a reflective target. The right hand photo shows a GPS and reflective target co-located control point for the TLS survey. Eight reflective targets were placed in the field during the two TLS surveys; three of them were co-located with GPS.

Two TLS campaigns were performed on May 24 to 25 and August 23 to 24, respectively. Each campaign scan was completed by twelve single scans from different viewpoints located inside and outside of the landslide area. Most scans were performed during the second day of each campaign (May 25 and August 24, 2010). The locations of these single scans were designed to capture 
the complete surface geometry of the study area and eliminate shadow areas. In order to transform the data from these single scans to the reference system of the first scan, eight reflective targets were placed in the study area. Each single scan could identify at least four reflectors. Three reflectors were co-located with continuous GPS as shown in Figure 2. The RISACN PRO software automatically determines the scanner's position and orientation based on the automatic recognition of these reflectors. Each single scan was automatically aligned during the survey and registered to the coordinate frame decided by the first single scan on site with the automatic matching technology provided by the RISACN PRO software package. The overall registration was refined based on GPS positions of these three reflective targets and transformed to a local reference system. The cloud points from each single scan were output from RISCAN-PRO with XYZ format. The Generic Mapping Tools (GMT, http://gmt.soest.hawaii.edu), an open-source software package widely utilized in the geophysical community for manipulating geographic and Cartesian data sets, was used for post processing and map plotting (Wessel and Smith, 1991, 1998).

One of the main open problems in today's laser scanning technique is dealing with a very huge dimension of point clouds, which make the data processing difficult. The scanner acquires up to 122,000 measurements/sec. Since each single scan covered a full 360 degrees in azimuth and 100 degrees in elevation, out to $600 \mathrm{~m}$, the raw point clouds included many more data than were of interest and required editing to become manageable. Data processing is based on three main steps that are performed by the GMT software package. The first step is to pre-edit the point clouds from each single scan with the BLOCKMEDIAN program included in the GMT software package. BLOCKMEDIAN eliminates redundant data according to a defined region of interest and then reads arbitrarily located $(x, y, z)$ triples and writes out a median position for every no-empty grid defined by a uniform grid spacing $(\mathrm{dx}$ and dy). Then the pre-processed point clouds from all single-scans are combined into a single file using Linux command "cat". The study area was limited to $120 \mathrm{~m}$ by $120 \mathrm{~m}$ based on the coverage of collected TLS point clouds and the size of the active massing. The grid size is set to $5 \mathrm{~cm}$ by $5 \mathrm{~cm}$. This process dramatically reduced the total data size. Secondly, the SURFACE program included in the GMT software package was used to interpolate the pre-edited TLS data to a continuous surface, which defines the digital surface model (DSM). This program utilizes a gridding method commonly known as minimum curvature. The method interpolates randomly spaced $(x, y, z)$ triples with a surface having continuous second derivatives and minimal total squared curvature. The details of this surface interpolation method were introduced by Smith and Wessel (1990). The interpolation process fills gaps within laser point clouds and makes the surface smooth. Figure 3 illustrates a topographic image plotted with the DSM data set from the first TLS survey in May 2010. The control point GPSO is outside of the landslide and the coordinate at this control point was set to $(0,0$,
0). Specific locations of other two GPS sites (GPS1, GPS2) at the two TLS surveying epochs are listed in Table 1. To aid visualization of the hill slope morphology and the landslide movement, two topographic profiles (Figure 4) were constructed from these DSMs. The changes in the height of ground surface along the profiles are plotted below each of the profiles. Locations of the two profiles are plotted in Figure 3. The greatest topographic changes were detected in the toe directly behind the repaired and flexed portion of the retaining wall. This section rose over one meter during the three-month study period. Visual analysis and the GPS data suggests that the significant rise in the toe formed by upward bulging behind the wall over a deeper rotational rupture surface that was augmented by superficial earth flows coming off of the steepening slopes above the wall.

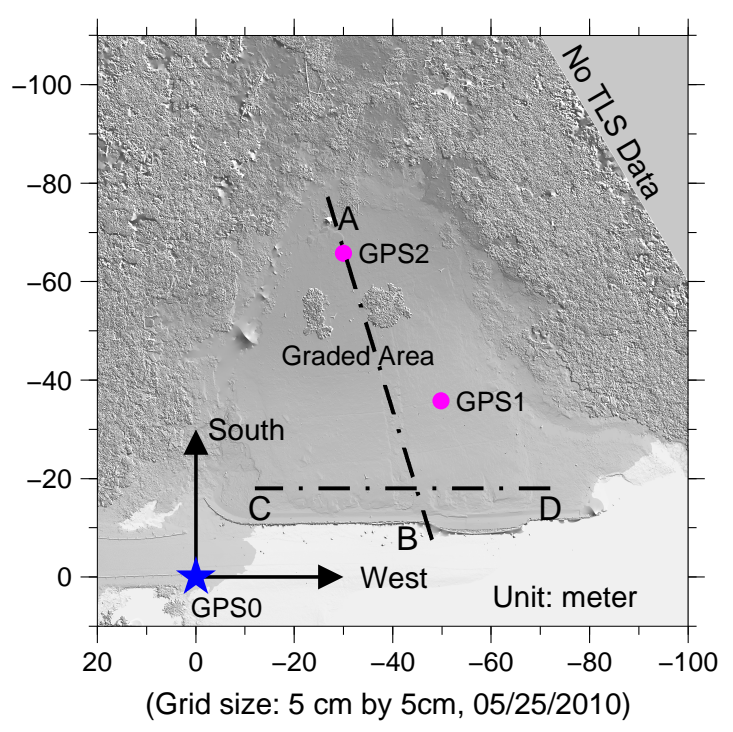

Figure 3. A topographic image plotted with the digital surface model (DSM) derived from laser point clouds acquired during the first TLS survey (May 24-25, 2010). The size of a unit grid of the DSM is $5 \mathrm{~cm}$ by $5 \mathrm{~cm}$.

Figure 5 illustrates the change in the surface topography (elevation) over the three-month period as derived from the two DSMs. The GRDMATH program included in the GMT package was applied to calculate the change of topography. The red patterns represent increased elevations, and the blue patterns represent decreased elevation. The graded and deforested lower portion is characterized by fairly smooth and continuous color patterns where as the vegetated portions are marked by very patchy color distributions. The upper portions of the landslide and the areas beyond the east and west flanks are covered by heavy vegetation (trees and bushes). There are few last laser returns from these dense vegetation areas. As a result, it is difficult to recover the bare earth surface. For this reason the first laser returns were used in this study. The DSM derived within the vegetated areas mostly represents the upper tree canopy of the forest. The light blue and 
Table 1. Coordinates of three control points equipped with co-located GPS and TLS reflectors.

\begin{tabular}{ccccccccccc}
\hline \multirow{2}{*}{ Unit: meter } & \multicolumn{3}{c}{ GPS0 } & \multicolumn{3}{c}{ GPS1 } & \multicolumn{3}{c}{ GPS2 } \\
\cline { 2 - 11 } & NS & EW & Vertical & NS & EW & Vertical & NS & EW & Vertical \\
\hline \hline $1^{\text {st }}$ TLS Survey $(\mathrm{m})$ & 0 & 0 & 0 & -35.77 & -49.84 & 10.06 & -65.78 & -30.0 & 18.63 \\
\hline $2^{\text {nd }}$ TLS Survey $(\mathrm{m})$ & 0 & 0 & 0 & -33.29 & -50.84 & 9.28 & -62.68 & -30.87 & 18.26 \\
\hline Displacement (m) & 0 & 0 & 0 & 2.48 & 1.0 & 0.78 & 3.1 & 0.87 & 0.37 \\
\hline
\end{tabular}
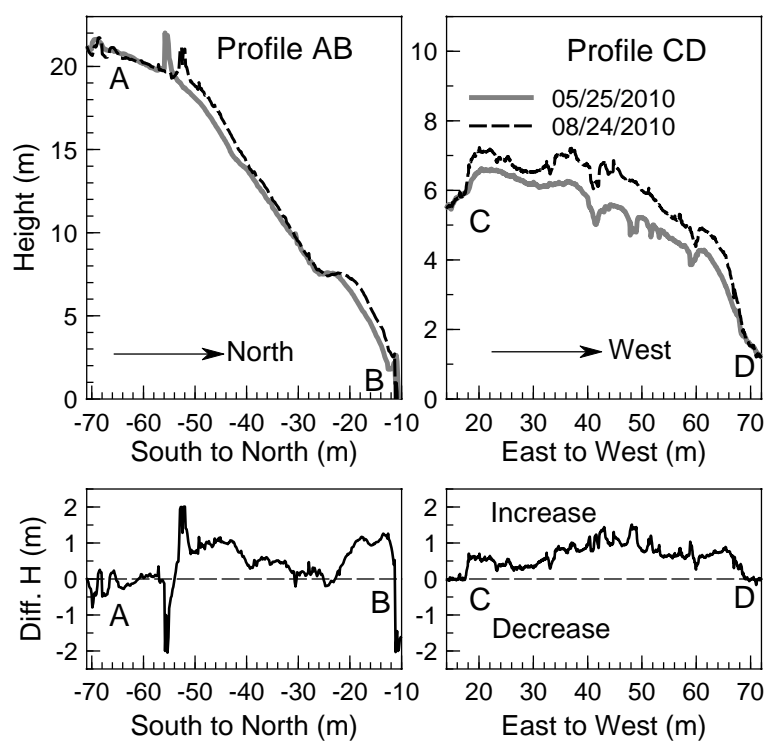

Figure 4. The top plots illustrate the topography along two crosssection profiles $A B$ and $C D$ illustrated in Figure 3 . The profiles are derived from the digital surface models (DSMs) of two surveys. The bottom plots illustrate the change of the height of the ground surface along these two profiles during the period from May 24 to August 25, 2010.

red interactive color patterns within the forested areas along the two flanks indicate very slight change of the elevation of vegetation. The deeper red and blue patchy patterns within the upper middle portion of the study area indicate large elevation changes caused by the displacement of tree tops in upper forest canopy and thus serve as a proxy for ground surface deformation. The moving mass as defined by the patchy distribution of deep blue and red colors is about $50 \mathrm{~m}$ wide and elongate in north-northwest direction. The location and direction of the limits defined by the patchy color distribution are coincident with the well defined flank escarpments in the higher portions of the landslide. Evidence for displacements along the flanks and head scarp over the period between the two TLS scans supports the contention that the patchy color distribution in the upper portions of the landslide is a function of deformation of ground surface and upper canopy displacement. The original design of the retaining wall was based

VERSITA on a size estimation using the locations of escarpments in the lower portions of the landslide. Figure 5 and site inspection indicates that the real moving mass is larger than previously suspected. Figure 6 shows the change of topography that occurred in the lower part of sliding mass. Vegetation on the lower portion of the landslide had been removed during the grading of the foot of the landslide and the construction of the retaining wall. Thus, the deformation derived from the two DSMs represents the change of bare ground surface. The displacement vectors and magnitude marked the two GPS sites were derived from continuous GPS measurements (see Figure 7). The outline of the retaining wall is colored with light blue indicating the slight decrease of the elevation of the top of the wall, which was caused by the downward tilting of the wall under the pressure of the moving and bulging mass. The difference derived from these two DSMs was used estimate displacement volumes. The GRDVOLUME program included in the GMT software package was used to calculate the volume change between these two TLS campaigns. This program reads a binary grid file and calculates the volume contained between the surface and a plane specified by a given elevation. It reports the area, volume, and average height (volume/area). The size of the elevated area (red area) is $2,382 \mathrm{~m}^{2}$ with an average height of $0.45 \mathrm{~m}$. The size of the depressed area (blue area) is $968 \mathrm{~m}^{2}$ with an average depth of $0.4 \mathrm{~m}$. The whole volumes of the elevated and depressed areas are $1,072 \mathrm{~m}^{3}$ and $387 \mathrm{~m}^{3}$, respectively. Their difference represents the mass transport from the upper part of the landslide to the lower part. The estimated volume of the total mass transport is $685 \mathrm{~m}^{3}$.

\section{Continuous GPS Monitoring}

Measuring superficial displacements is the simplest way to observe the evolution of landslides and to analyze the kinematics of their movements. Continuous GPS monitoring is essential in establishing the rate and pattern of superficial movements. We equipped a semi-permanent GPS array at the landslide area including two rover stations (GPS1 and GPS2, see Figure 3) and one reference station. The reference GPS was installed on the roof of a one-floor building in the National Forest Park administration center, which was equipped with a Trimble NetR8 GPS receiver and a Zephyr Geodetic antenna. AC power was available at this site. These two rover GPS stations were equipped with Topcon GB1000 receivers and PG-A1 antennas, which were powered by external batteries. The baseline length between the reference GPS 


\section{Journal of Geodetic Science}

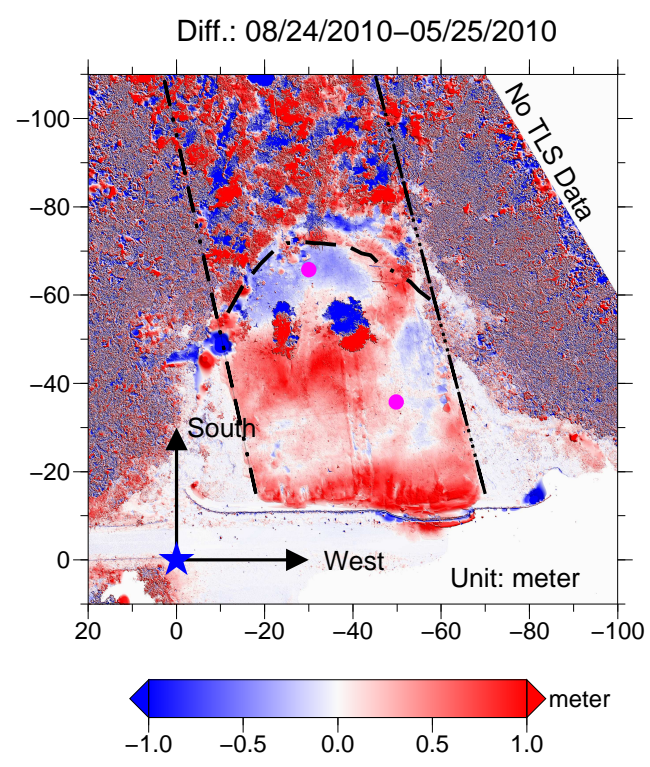

Figure 5. The change of the ground-surface elevation during the three-month period derived from the digital surface models (DSMs) of two TLS surveys. Red and blue color patterns represent increasing and decreasing of the elevation of ground surface, respectively. This image draws out the limits of the landslide deformation area.

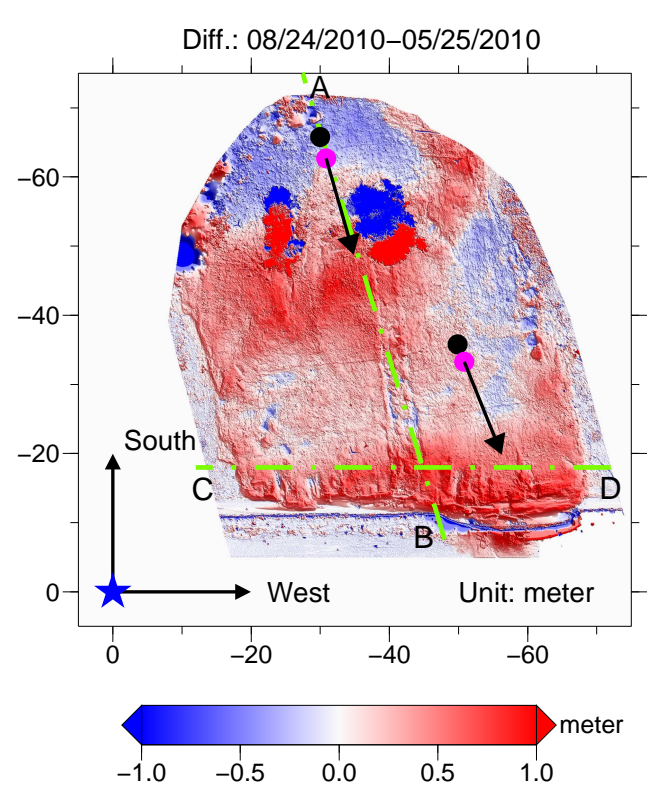

Figure 6. The change of the ground-surface elevation of the lower part of the landslide. Same as Figure 5 but the areas covered by vegetation have been cut off. The size of the elevated area (red) is $2382 \mathrm{~m}^{2}$ with an average height of $0.45 \mathrm{~m}$. The size of the depressed area (blue) is $968 \mathrm{~m}^{2}$ with an average depth of $0.4 \mathrm{~m}$. The volumes covered by the red and blue areas are $1072 \mathrm{~m}^{3}$ and $387 \mathrm{~m}^{3}$, respectively. The sliding directions at the lower and higher GPS sites are $\mathrm{NW}_{2} 2^{\circ}$ and $\mathrm{NW} 15^{\circ}$ (see Figure 8). The black and pink circles represent the locations of each GPS antenna on May 25 and August 24, 2010, respectively.
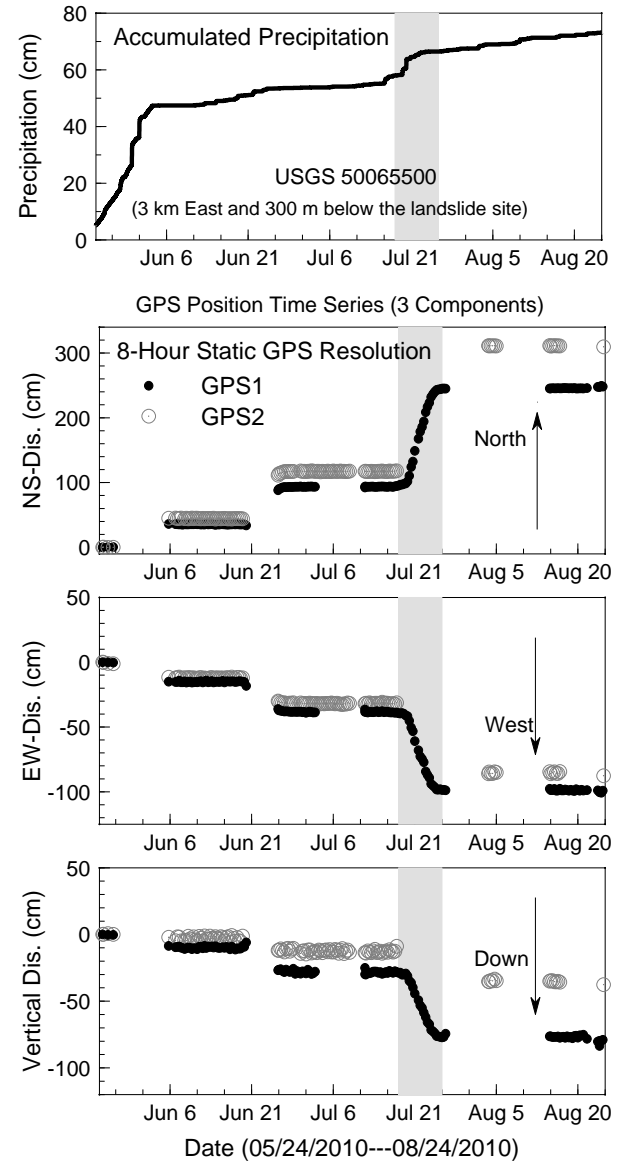

Figure 7. Plots showing rainfall vs. landslide movements during the three-month period from May 24 to August 24, 2010. The top plots illustrate accumulated precipitation at a vicinity USGS weather station. The bottom plots illustrate threecomponent displacement time series recorded by two GPS units installed on the landslide (see Figure 3). Each measurement represents an average position within a period of 8 hours (3 measurements/day).

and rover GPS is about $1.95 \mathrm{~km}$. The sampling rate of GPS raw data is 1 sample per 15 seconds. The Topcon software package Topcon Tools (V7.2) was applied in GPS data processing. Relative displacements (three-component: NS-north to south, EW: east to west, and Vertical) between the rover and reference GPS antennas are calculated using 8-hour sessions with static GPS method and 1-hour sessions with rapid static GPS method. Both static and rapid static GPS methods involve using two GPS antennas to simultaneously measure a baseline vector. The landslide displacements are described by the changes of the baseline length between a reference GPS antenna and a rover GPS antenna in this study. The static GPS method requires a long observation time from a few hours to a day, while the rapid static GPS method requires as short as a few minutes observation time. According to our recent research on GPS landslide monitoring in Puerto Rico (Wang 2010) 
and other empirical studies about the precision of GPS (Eckl et al., 2001; Soler et al., 2006; Geng et al., 2010; Firuzabadi and King, 2010), both 8-hour session static and 1-hour session rapid static GPS can provide sub-centimeter precision for a baseline less than $2 \mathrm{~km}$.

The three-component displacement time series measured at the two rover GPS sites are plotted in Figure 7. The top plot illustrates the accumulated rainfall data recorded by a USGS weather station, which is about $3 \mathrm{~km}$ east and $300 \mathrm{~m}$ down to the landslide site. The sampling rate of the rainfall data is every 15 minutes per measurement. The bottom plots illustrate landslide movements. Each single point represents an average position derived from an 8-hour session of the 24-hour continuous GPS observations (3 positions/day). There are many gaps within the time series because of the failure of power supplies at rover GPS stations. Both the accumulated precipitation and landslide displacement traces show step-like shape. The coincidence of the heavier rainfall pulses and landslide displacements indicates a causal relationship between the rainfall and displacement. It appears that landslide displacement only occurs during heavier rainfall events and that little or no landslide activity occurs otherwise.

There were considerable differences between the displacements at the two GPS sites. The higher GPS (GPS2) moved half meter more than the lower GPS (GPS1) towards north direction, while the displacements along the west direction at the two sites are comparable. The differential displacements between the two GPS sites within the horizontal plane indicates there was mass transport from the upper portion into the lower portions of the landslide resulting in the increased height of the lower portion as shown in Figure 5. The total displacements during the 3-month period at the higher GPS (GPS2) are $3.10 \mathrm{~m}, 0.87 \mathrm{~m}$, and $0.37 \mathrm{~m}$ towards north, west, and down directions, respectively (see Table 1 ), which can be resolved into a NW15 net slip of 3.24 meters at a plunge angle of 6 . The three-component displacements at the lower GPS (GPS1) are $2.48 \mathrm{~m}, 1.0 \mathrm{~m}$, and $0.78 \mathrm{~m}$ towards north, west, and down directions, respectively, which can be resolved into a NW22 ${ }^{\circ}$ net slip of 2.78 meters at a plunge angle of 17 . A sub-horizontal slip angle below the upper GPS station (GPS2) is consistent with the displacement of the higher and flatter portion of the graded slopes exhibited in TLS profile AB on Figure 4. The more steeply inclined slip angle and lesser displacement of the lower GPS1 is consistent with the interpretation of a rotational slide surface occurring below the lower slopes above the retaining wall. The greater displacement of GPS2 and the increase in the volume of lower landslide mass suggest that the displacements of the lower graded portions of the landslide are being driven by displacement of upper portions. Field observations of the flanks and head scarp over the three-month study period confirmed displacements along the flanks and the continued retreat of the head scarp. Figure 8 shows the slip vectors in the horizontal plane at the two GPS sites, indicating a steady sliding direction during the three-month period. The sliding directions at the upper and lower GPS sites are
$\mathrm{NW} 15^{\circ}$ and $\mathrm{NW} 22^{\circ}$, respectively.

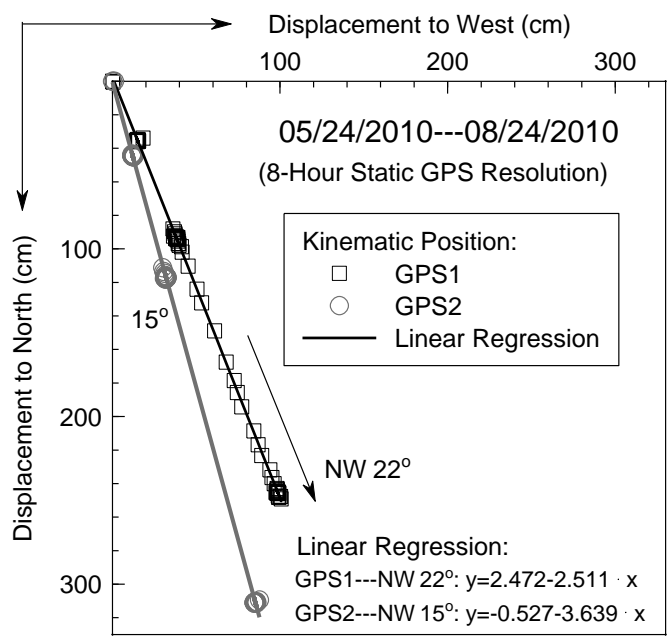

Figure 8. A plot showing the slide vectors at the lower and upper GPS sites (GPS1 and GPS2) during the time range from May 24 to August 24, 2010. The slide directions at the upper and lower GPS sites are $\mathrm{NW} 15^{\circ}$ and $\mathrm{NW} 22^{\circ}$, respectively.

Rainfall precipitation has been identified as one of the most important factors controlling landslides in Puerto Rico (e.g., Monroe, 1964, 1979; Jibson, 1986, 1989; Larsen and Simon, 1993; Larsen and Torres-Sanchez, 1996, 1998; Wang 2010). There were heavy rainfalls in the landslide area during the later part of July, 2010 that triggered a rapid 2-3 meter displacement of the landslide from July 18 to 25 as shaded in Figure 7 that leaded to the rupture of the retaining wall. The renewed and more rapid displacement indicates pulse-like motions that can be simulated by a simple sinusoidal waveform. In this study, a fling-step was used to approximate the displacement time series of the renewed rapid sliding as a function of duration (or period) and amplitude (or height) of the displacement data step. Figure 9 illustrates the waveforms (acceleration, velocity, and displacement) of a fling-step pulse. The mathematical models of the fling-step, as well as its velocity and acceleration time series can be expressed as follows:

$d(t)=\left\{\begin{array}{l}0 \\ \frac{H}{T}\left(t-t_{0}\right)-\frac{H}{2 \pi} \sin \left[\frac{2 \pi}{T}\left(t-t_{0}\right)\right] \begin{array}{l}t<t_{0} \\ t_{0}<t<T+t_{0} \\ T+t_{0}<t\end{array}\end{array}\right.$

$$
v(t)= \begin{cases}0 & t<t_{0} \\ \frac{H}{T}-\frac{H}{T} \cos \left[\frac{2 \pi}{T}\left(t-t_{0}\right)\right] & t_{0}<t<T+t_{0} \\ 0 & T+t_{0}<t\end{cases}
$$


$a(t)= \begin{cases}0 & 2 \pi \cdot H \\ \frac{T^{2}}{2} \sin \left[\frac{2 \pi}{T}\left(t-t_{0}\right)\right] & t<t_{0} \\ 0 & t_{0}<t<T+t_{0} \\ & T+t_{0}<t\end{cases}$

where $\mathrm{T}$ is the duration (or period) of the fling-step; $\mathrm{H}$ is the height of the displacement step. Both $\mathrm{T}$ and $\mathrm{H}$ can be directly measured from the observed displacement time series. The synthetic fling-step displacement and its corresponding velocity and acceleration time series are plotted in Figure 10 along with 1-hour rapid static GPS measurements (24 measurements/day). All these three-component displacement steps were modeled by fling-steps with a common period ( $\mathrm{T}$ ) of 192 hours (8 days, from July 18 to $25)$ and different permanent displacements (H) (NS: $148 \mathrm{~cm}$, EW: $-60 \mathrm{~cm}$, vertical: $-48 \mathrm{~cm}$ ). The mathematical model of the displacements provides a precise way of estimating the velocity and acceleration time series. It is clear that the whole process of the renewed displacement is considerably smooth. The intense rainfall on July 19 (9 cm within 20 hours) did not immediately trigger faster sliding. The total renewed displacement can be characterized as an accelerated process and a decelerated process. The peak accelerations and decelerations were achieved at the beginning of the third and sixth days after the start of the displacement pulse, while the peak velocities were achieved at the beginning of the fourth day after the initiation of the rapid sliding. The maximum accelerations for these three components are $0.025 \mathrm{~cm} / \mathrm{h}^{2}, 0.01 \mathrm{~cm} / \mathrm{h}^{2}$, and $0.008 \mathrm{~cm} / \mathrm{h}^{2}$ for NS, EW, and vertical components, respectively. The maximum velocities are $1.6 \mathrm{~cm} / \mathrm{h}, 0.7 \mathrm{~cm} / \mathrm{h}$, and $0.5 \mathrm{~cm} / \mathrm{h}$. The time differential between the initiation of the heavy rainfall and maximum sliding velocity is probably due to the time it takes to build up pore water pressure in the basal rupture surface. This is consistent with a deeper landslide seated in weathered bedrock rather than superficial sliding of the upper colluvial mass. Fling-step models have been widely utilized to simulate near-fault displacement pulse during strong earthquakes (e.g., Kalkan and Kunnath, 2006). The present analysis shows that rainfall induced landslide displacement pulses can also be characterized by a fling-step model.

\section{Discussion and Conclusions}

TLS represents an non-invasive, effective and rapid solution to produce economical and accurate terrain models which enable to detect deformation of an entire surface of interest. In comparison to other topographic and photogrammetric surveying techniques, TLS seems to be a suitable approach for study ground surface deformation in a large area with a very high level of detail. The laser scanning technology does not require direct contact (contact-free) with the scanned object, which makes the TLS technique an efficient tool to identify landslide in vegetated or other kind inaccessible areas. Our TLS data clearly identified the
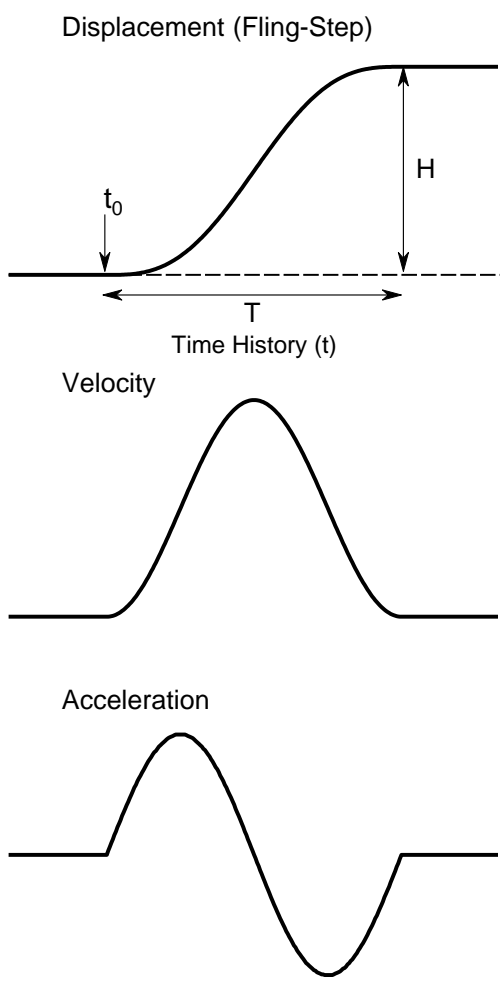

Figure 9. The waveforms (displacements, velocities, and accelerations) of a fling-step pulse. (Note: curves are normalized by maximum acceleration, velocity, and displacement.)

limits of the actively moving landslide mass even though covered by vegetation. From a logistic point of view, the new generation TLS equipment and its accessories (tripods, generator, and laptop) are easily portable and all of the field work can be handled by two people. TLS on the other hand also has its shortcomings. The laser scanner is not suitable for use in adverse rainy weather conditions. The water drops in air or on reflectors may cause noise or false signals in the measurements. The average accumulated rainfall at the El Yunque rainforest is over four meters per year (The Climate Source Inc., 2002). It rains a few times nearly every day such that the field surveys were often interrupted and delayed by rain. In fact, the field scanning could have been finished in one day without the rainfall interruptions. It would be difficult assess ground deformation in a continuous time domain using the laser scanning technique alone. Fortunately, the GPS method can overcome the temporal limitation of TLS and GPS can work continuously under any weather conditions. Continuous GPS monitoring provides information of the ground deformation in the temporal domain. However, GPS only measures displacements at a discrete point. The two techniques complete each other and provide data on landslide development in a continuous spatial-temporal domain. The data acquired in this study have demonstrated the effectiveness and 
Local Rainfall Data (USGS 50065500)
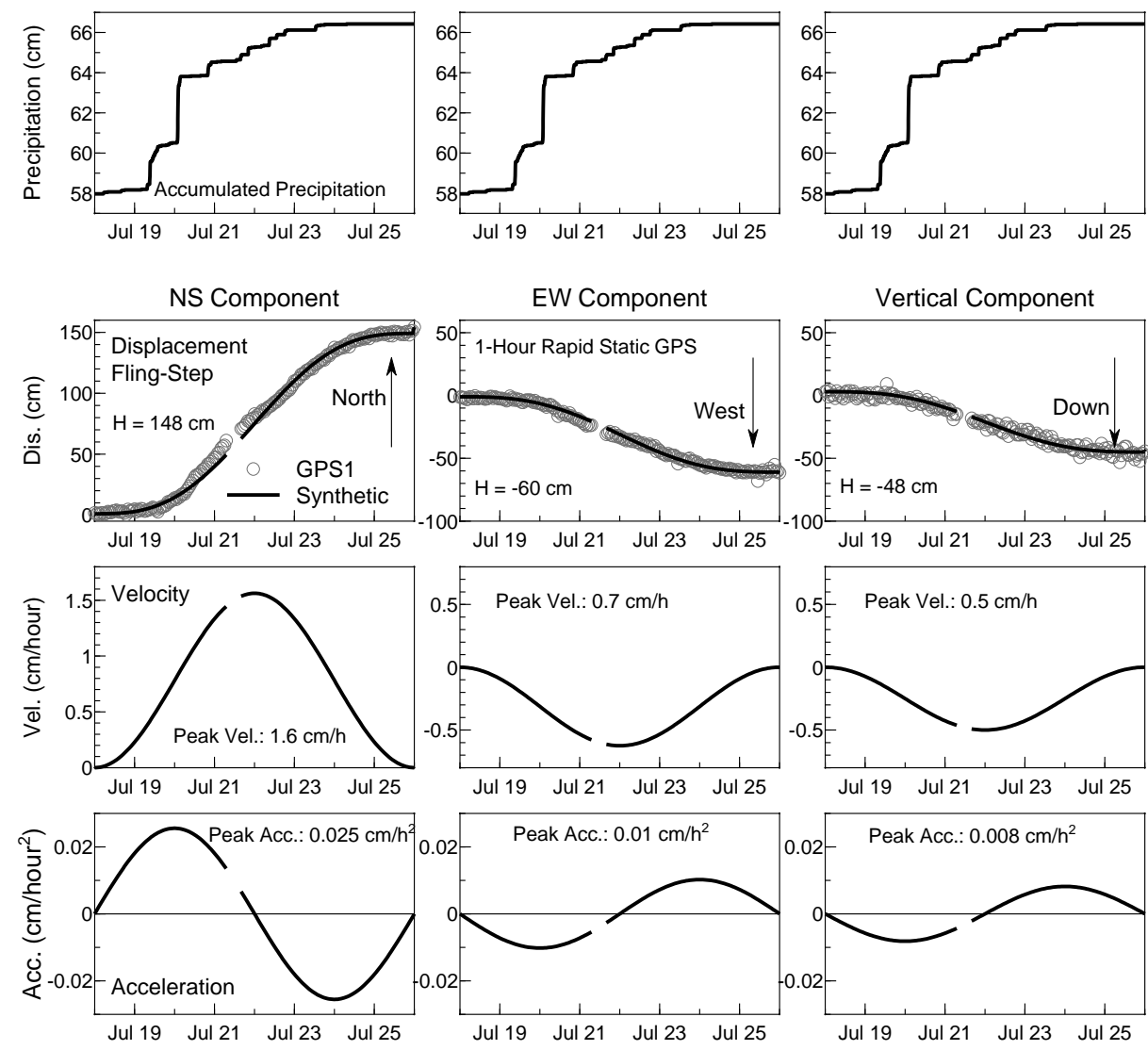

Date (07/18/2010---07/25/2010, 192 Hours)

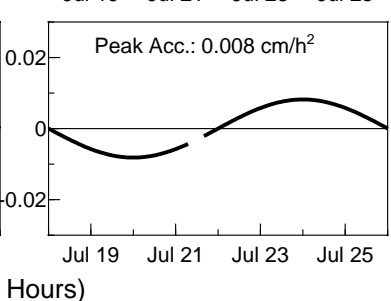

Figure 10. A comparison of synthetic and observed landslide displacement time series. The top row illustrates the local accumulated precipitation. The second row illustrates measured and synthetic displacement time series shaded in Figure 7 from July 18 to 25,2010 . The period (T) of the fling-step function is 192 hours (8 days) for all three components. The heights $(\mathrm{H})$ are $148 \mathrm{~cm},-60 \mathrm{~cm}$, and $-48 \mathrm{~cm}$ for NS, EW, and vertical components, respectively. There were data missing during late of July 21, 2010. Each measurement represents an average position within a period of 1-hour (24 measurements/day).

power of the integrated applications of TLS and GPS techniques in landslide study.

Although high powered models can be derived from the TLS method and the method allows for the acquisition of very dense and accurate point clouds in a fast and simple way, the management and process of the large amount of data is still a challenge for most applications. Most software packages available for processing TLS data are commercial and based on the Microsoft Windows operation system. The cost of a TLS project could be considerable largely because of the high cost of the available commercial software. The present study introduces an approach of using an open-source software package (GMT) to process TLS data. The GMT software package has proven efficient in handing the huge TLS data sets. The open-source software could be a solution for effective TLS data processing especially if more modules are added

\section{VERSITA}

in future. Data acquisition, processing, and interpolation methods utilized in the present study can be applied to study any mass transport process and surface deformation such as subsidence, avalanche, landslide, debris flow, glacier mass balance, and snow melt. The present study has exploited the capabilities of the TLS and GPS instruments and methods and promotes the integration of these techniques in the geosciences community.

\section{Acknowledgements}

This study was initiated through the discussion with Charles Meertens (UNAVCO) and John S. Oldow (University of Dallas) and benefited as well from discussions with Robert W. King (MIT). Reviews by Alojz Kopacik (Slovak University of Technology in Bratislava), Ana Paula C. Larocca (University of Sao Paulo) and 
one anonymous reviewer led to substantial improvements in this paper. Manuel Ortiz, Guillermo Aponte, and Sidney Salyer of El Yunque National Forest are appreciated for their kindly supporting the field instrumentation and monitoring. Undergraduates Gustavo Galan, Patricia Tous and Arlenys Ramirez Rivera assisted in the field work. We appreciate their hard work in the field. This study was funded by NSF project (EAR-0842314) and the TLS equipment was provided by UNAVCO.

\section{References}

Abellan A., Vilaplana J.M., Martinez J., 2006, Application of a long-range Terrestrial Laser Scanner to a detailed rockfall study at Vall de Nuria (Eastern Pyrenees, Spain), Engineering Geology, 99(3-4):136-148.

Bruckl E., Brunner F.K., Kraus K., 2006, Kinematics of a deep-seated landslide derived from photogrammetric, GPS and geophysical data, Engineering Geology, 88:149-159.

Casula G., Mora P., Bianchi M.G., 2010, Detection of terrain morphologic features using GPS, TLS, and land surveys: "Tana Dells Volpe" blind valley case study, Journal of Surveying Engineering, 136(3):132-138. DOI:10.1061/(ASCE)SU.1943-5428.0000022

Coe J.A., Ellis W.L., Godt J.W., Savage W.Z., Savage J.E., Michael J.A., Kibler J.D., Powers P.S., Lidke D.J., Debray S., 2003, Seasonal movement of the Slumgullion landslide determined from Global Positioning System surveys and field instrumentation, July 1998-March 2002, Engineering Geology, 68:67-101.

Eckl M.C., Snay R.A., Soler T., Cline M.W., Mader G.L., 2001, Accuracy of GPS-derived relative positions as a function of interstation distance and observing-session duration, J. Geod., 75:633-640.

Firuzabadi D., King R.W., 2010, GPS precision as a function of session duration and reference frame using multi-point software, GPS Solutions, (in press).

Geng J., Meng X., Teferle R.N., Dodson A.H., 2010, Performance of precise point positioning with ambiguity resolution for 1 - to 4-hour observation periods, Surv. Rev., 42:155-165.

Gili J.A., Corominas J., Rius J., 2000, Using Global Positioning System techniques in landslide monitoring, Engineering Geology, 55:167-192.

Jibson R.W., 1986, Evaluation of landslide hazards resulting from the 5-8 October 1985 storm in Puerto Rico, U.S. Geological Survey Open-File Report 86-26.
Jibson R.W., 1989, Debris flows in southern Puerto Rico. Geol. Soc. Am., Special paper 236: 29-55.

Kalkan E., Kunnath S.K., 2006, Effects of fling-step and forward directivity on seismic response of buildings, Earthquake Spectra, 22(2):367-390.

Larsen M.C., Simon A., 1993, Rainfall-threshold conditions for landslides in a humid-tropical system, Puerto Rico, Geografiska Annaler, 75A (1-2):13-23.

Larsen M.C., Torres-Sánchez A.J., 1996,Geographic relations of landslide distribution and assessment of landslide hazards in the Blanco, Cibuco, and Coamo river basins, Puerto Rico, U.S. Geological Survey Water-Resources Investigations Report, 95-4029, 56.

Larsen M.C., Torres-Sánchez A.J., 1998, The frequency and distribution of recent landslides in three montane tropical regions of Puerto Rico, Geomorphology, 24(4):309-331.

Lichti D.D., Jamtsho S., 2006, Angular resolution of terrestrial laser scanners, Photogrammetric Record, 21:141-160.

Malet J.P., Maquaire O., Calais E., 2002, The use of Global Positioning System techniques for the continuous monitoring of landslides application to the Super-Sauze earthflow (Alpesde Haute-Province, France), Geomorphology, 43:33-54.

Monroe W.H., 1964, Large retrogressive landslides in north-central Puerto Rico. U.S. Geological Survey Professional Paper 501, Chapter B, B123-B125.

Monroe W.H., Map showing landslides and areas of susceptibility to landsliding in Puerto Rico. U.S. Geological Survey Miscellaneous Investigations Series Map I-1148, 1 sheet, scale 1:240,000, 1979.

Monserrat O., Crosetto M., 2008, Deformation measurement using terrestrial laser scanning data and least squares 3D surface matching, ISPRS Journal of Photogrammetry and Remote Sensing, 63(1):142-154.

Mora P., Baldi P., Casula G., Fabris M., Ghirotti M., Mazzini E., Pesci A., 2003, Global Positioning Systems and digital photogrammetry for the monitoring of mass movements: application to the Ca di Malta landslide (northern Apennines, Italy), Engineering Geology, 68:103-121.

Peyret M., Djamour Y., Rizza M., Ritz J.F., Hurtrez J.E., Goudarzi M.A., Nankali H., Chery J., Le Dortz K., Uri F., 2008, Monitoring of the large slow Kahrod landslide in Alboz mountain range (Iran) by GPS and SAR interferometry, Engineering Geology, 100:131-141.

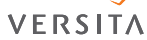


Psimoulis P., Ghilardi M., Fouache E., Stiros S., 2007, Subsidence and evolution of the Thessaloniki plain, Greece, based on historical leveling and GPS data, Engineering Geology, 90:55-70.

Sato H.P., Abe K., Ootaki O., 2003, GPS-measured land subsidence in Ojiya City, Niigata Prefecture, Japan, Engineering Geology, 67:379-390.

Smith W.H.F., Wessel P., 1990, Gridding with continuous curvature splines in tension, Geophysics, 55(3):293-305.

Soler T., Michalak P., Weston N.D., Snay R.A., Foote R.H., 2006, Accuracy of OPUS solution for 1- to 4-h observing sessions, GPS Solution, 10:45-55, DOI:10.1007/s10291-005-00087-3

Squarzoni C., Delacourt C., Allemand P., 2005, Differential single-frequency GPS monitoring of the La Valette landslide (French Apls), Engineering Geology, 79:215-229.

Tagliavini F., Mantovani M., Marcato G., Pasuto A., Silvano S., 2007, Validation of landslide hazard assessment by means of GPS monitoring technique a case study in the Dolomites (Eastern Alps, Italy), Natural Hazards and Earth System Sciences, 7:185-193.
Teza G., Galgaro A., Zaltron N., Genevois R., 2007, Terrestrial laser scanner to detect landslide displacement fields: a new approach, International Journal of Remote Sensing, 28:3425-3446.

Teza G., Pesci A., Genevois R., Galgaro A., 2008, Characterization of landslide ground surface kinematics from terrestrial laser scanning and strain field computation, Geomophology, 97:424-437.

The Climate Source Inc., 2002, PRISM 19631995 mean annual precipitation, Puerto Rico. http://www.climatesource.com/pr/fact_sheets/prppt_xl.jpg (Last Accessed Date: December 4, 2010).

Wang G., 2010, Kinematics of the Cerca del Cielo, Puerto Rico landslide derived from continuous GPS observations, Landslides, (submitted).

Wessel P., Smith W.H.F., 1991, Free software helps map and display data, EOS Trans. AGU, 72:441.

Wessel P., Smith W.H.F., 1998, New improved version of the Generic Mapping Tools released, EOS Trans. AGU, 79:579. 